These two genera are now considered to form a single family. The distribution of Proterhinus, centred in Hawaii and with outlying species in other Pacific islands, is comprehensible, as is also the occurrence of related forms in New Zealand. But no explanation suggests itself for the existence of another relative in the Canaries, when no representative of the family has come to light in any other part of the world-even where the fauna has been intensively collected.

The degree of endemism is very high. Exeluding wide-ranging forms, few or no species are common to the Marquesas and Hawaii or Samoa, the nearest high islands of which the fauna is well enough known for comparison. Among species the degree of endemism is probably lower than in Hawaii, but of the same order (that is, approaching 80 per cent) ; among genera it is much lower.

The proportion of endemic species restricted to a single island is apparently higher than in Samoa and of the same order as in Hawaii. For example, there is, as in many remote islands, a great development of endemic Cureulionidæ, and, in the otiorrhynchine section, the number and diversity of species, each restricted to a single island, indicate that the archipelago is of considerable age. Like phenomena are noted among the HemipteraHomoptera, while, on the other hand, in one family of Hemiptera-Heteroptera a genus has developed into many closely allied endemic species, some of which range over several islands. Possibly these latter forms originated too recently to have diverged into separate species. It is too early to state whether any evidence is forthcoming of an increase in the habitable age of the islands from south-east to north-west, like that of which there is some indication in the Hawaiian archipelago.

Nor are generalisations as to the origin of the fauna yet possible; for, some groups of animals exhibit close relationships with the fauna of Hawaii, others with that of the south central Pacific islands lying to the south-west. Among the former are the Hemiptera-Homoptera, among the latter the Hemiptera-Heteroptera, and the endemic birds and land snails, which have little in common with those of Hawaii. Botanists have stressed the existence of important, though secondary, affinities between the Marquesan and Hawaiian floras.

Deductions bearing on past land connexions in the Pacific are also left until the fauna has been fully worked out. While the almost entire absence of coral reefs has been attributed to rapid subsidence, alternating elevation and subsidence have also been postulated. In either case, the number of species restricted to a single island indicates that the individual islands have been separated for a long period, if time be regarded in terms of what is needed for the formation of species.

The sections on association of endemic insects and plants, and the bearing of the investigation on agricultural and medical problems, cannot be discussed here. Enough has been written to show the nature of the questions discussed. The Survey may be congratulated on an excellent start.

\title{
Some Problems of Food Preservation
}

\section{$\mathrm{T}$} $\mathrm{HE}$ problems involved in the freezing, storage and transport of New Zealand lamb have recently been examined by the Food Investigation Board, in co-operation with the Empire Marketing Board, the New Zealand Department of Scientific and Industrial Research, the New Zealand Meat Producers' Board and the New Zealand Tonnage Committee representing the shipping lines trading between Great Britain and New Zealand. ${ }^{1}$ The investigation involved an analysis of the physical conditions in the various storage chambers through which the meat passed and an examination of the effects of the environment on the quality and appearance of thecarcases, asestimated from the loss of 'bloom'. Bloom is the freshly-killed appearance of the meat and is dependent upon the appearance of the superficial tissues, the exposed muscle, fat and connective tissue. It is affected by the following factors: the rate of cooling and freezing, which determines the opacity of the superficial connective tissue and, indirectly, the colour of the visible muscle; the amount of drying, excessive desiccation producing marked loss of colour in the muscle; the formation of methæmoglobin from hæmoglobin on prolonged storage, that conversion being hastened by sweating ; and finally, excessive sweating, which also results in swelling of the connective tissue fibres with increase in their opacity.

When meat is frozen, the structure of the muscle is changed, so that on thawing it is not so resilient and there is a leakage of free fluid, usually referred to as 'drip'. Freezing probably denatures certain of the proteins so that they lose some of their power to hold water. At a temperature constantly below $-8^{\circ} \mathrm{C}$. other changes, such as those due to autolysis, microbial growth or hydrolysis and oxidation of the fat, are only slight. It is therefore the alterations in the physical properties of the meat which are of the most importance. They are indicated by loss of weight as well as by loss of bloom.

The survey has shown that there is no need for radical alterations of technique, although improvements at each stage of the chain of treatment are possible. It has been found that bloom is affected not only by the immediate ante-mortem treatment of the sheep but also by such factors as breed, diet, age at killing, etc. Southdown crosses were found to have a good initial bloom and that was correlated with a higher concentration of hæmoglobin in the superficial muscle; older animals had a better bloom than younger of the same breed. Starvation prior to slaughter had

No. 3291, VoL. 130] 
little effect on bloom but strenuous exercise was definitely deleterious, the superficial muscle being of a dark reddish-grey colour. The important conclusion is drawn that, within limits, carcases having the superior initial bloom will maintain this superiority throughout the subsequent chain of treatment.

After slaughter the carcases are cooled, preferably at a low temperature $\left(12^{\circ} \mathrm{C}\right.$. $)$, and in air near saturation point. Hanging for 10-12 hours should precede freezing. At this temperature the rate and extent of loss of weight during hanging are reduced, so that the superficial desiccation is also less. The rate of loss of weight on subsequent freezing is also lower with an adequate period of cooling.

Each chain in the passage of the meat from the freezing chambers in New Zealand to the cold stores in London was examined in detail. The advantages and disadvantages of the different systems of refrigeration are pointed out. The danger points are the transport from store to ship in New Zealand and from ship to store in Great Britain. Recommendations to minimise the delays at these points in the chain are given in the report: too long exposure of the carcases to a high temperature results in softening and sweating. It was found that the average loss of weight during cooling, freezing, 28 days storage in New Zealand, ocean transport and 28 days storage in Great Britain was 3.65 per cent in prime quality lambs and slightly greater in second quality carcases. The longer carcases are stored the greater is the loss of weight and, therefore, of bloom. Since loss of weight occurs to some extent even under the best conditions of storage, it appears necessary, to prevent any loss of weight or bloom, to cover the carcases with bags impermeable to aqueous vapour. The ideal bag, however, has still to be evolved.

Another problem of cold storage is the prevention of the yellowing of the abdominal fat in rabbits. Even when kept at a temperature of $-10^{\circ}$ to $-12^{\circ} \mathrm{C}$., the superficial fat, in addition to becoming rancid, acquires on its exposed surface a pronounced yellow colour, varying in tint from light yellow to dark orange. The discoloration extends to a depth of a few millimetres and in advanced stages the yellow fat is wax-like in nature and can generally be peeled off from the white fat beneath. The period between the killing of the rabbits in Australia and New Zealand and their marketing in Great Britain varies but is on the average 4-5 months. The longer the storage the more frequently is the yellowing found.

$J$. R. Vickery has recently carried out experiments on the nature and cause of this yellowing: the results obtained have indicated the measures which can be adopted to prevent it. ${ }^{2}$ It was found that the rate of development of yellowing during storage in the frozen condition was dependent, within limits, upon the duration and temper. ature of storage in the pre-freezing period: thus storage for two days at atmospheric temperature prior to freezing enhanced the yellowing to a

No. 3291, Vou. 130] degree approximately equivalent to one month's storage at $-5^{\circ} \mathrm{C}$. The intensity and depth of penetration of the yellowness were proportional to the duration of storage in the frozen condition at a given temperature, and were greater the higher the temperature. At $-10.5^{\circ} \mathrm{C}$. the market value of the rabbits is affected within three to five months according to the nature of the pre-freezing treatment. At $-18^{\circ} \mathrm{C}$. yellowing is almost eliminated.

The yellow material accompanies the soaps on saponification of the fat and can be separated from the fatty acids by the use of ice-cold petroleum ether in which it is insoluble. It apparently has its origin in the oxidation of the linoleate glycerides under the influence of an oxidase present in the fatty tissue, the action of which is markedly accelerated by the presence of moisture and hæmoglobin. The pigment is probably an unsaturated ketonic compound.

The measures required to prevent yellowing are, therefore, the exclusion of oxygen and hæmoglobin, shortening of the time of storage and storage at a lower temperature. Air can be excluded from the abdominal fat by covering it with the muscle of the abdominal wall, hæmoglobin by thorough bleeding of the animals and cleaning the fat of all superficial blood: but a lower temperature of storage will still be necessary to prevent appreeiable yellowing over periods of about six months.

Dr. Vickery also made a few observations on the development of rancidity in the fat of rabbits. It was found to develop on storage much more rapidly than is usually the case with other animals: its onset can be retarded by excluding air from the fat and storage at temperatures below $-10.5^{\circ} \mathrm{C}$., at which temperature rancidity may be expected in five months.

Further information on problems of food preservation can be obtained from the Index to the literature issued twice a year by the Low Temperature Research Station. The first number of vol. 4 contains a review of noteworthy developments during $1930-31,{ }^{3}$ to some of which brief reference may be made. Troy and Sharp have investigated the condition of lactose in dried milk, condensed milk and ice-cream. In dehydrated milk the lactose is present as an equilibrium mixture of non-crystalline $\alpha$ - and $\beta$-lactose; when milk is dried slowly below $50^{\circ} \mathrm{C}$., lactose crystallises in the $\alpha$-hydrate form. These facts are considered to explain the caking of milk powder and 'sandiness' in ice-cream. Parisi has shown that the velocity of crystallisation depends on the velocity of transformation between $\alpha$ - and $\beta$-lactose, and is influenced considerably by the hydrogen ion concentration of the solution. Lampitt and Bushill have shown that fat in milk dried by the rollerprocess can nearly all be removed by direct extraction with a solvent, while only a small proportion can be extracted in this way from spray-dried milk. The difference is attributed to the condition of the lactose; its crystallisation appears to result in 'freeing' of fat. 
Slight hydrogenation of the fat has been found of value in the case of a number of foodstuffs : it prevents rancidity in tallow and lard; it stabilises the fat in butter without destroying its flavour; it bleaches palm oil without hardening it; and finally, in the case of cacao-butter, it prevents the 'blooming' of chocolates.

Morgan, Field and Nichols have found that the vitamin $\mathrm{C}$ content of prunes and apricots need not be reduced by dehydration or treatment with sulphur dioxide when the processes are carried out under properly controlled conditions. Clow and Marlatt state that the vitamin $\mathrm{C}$ content of tomatoes is the same whether ripening occurs in the field, in the greenhouse or is brought about artificially with the aid of ethylene. It has been shown by Kohman, Eddy and Zall that considerable loss of vitamin $\mathrm{C}$ and some loss of vitamin B occur in the canning of tomatoes in the presence of air : in steam this loss is not observed. Vitamin $\mathrm{A}$ is the most, and vitamin $\mathrm{C}$ the least stable. To preserve the vitamins it is essential to guard against oxidation during canning.

Morris and Bryan have found that the method of manufacture of steel may have a considerable influence on its rate of corrosion. In solutions of low acidity the main points of attack are the pits and seams of the tin, whilst in those of high acidity, the exposed portions of the tin are particularly liable to corrosion. It is recommended that citric acid be added to fruit of low acidity, that the sugar used be free from sulphur compounds (which have a considerable influence on the corrosion of tins) and that beet sugar be used, or agar added to inhibit corrosion.

${ }^{1}$ Department of Scientiflc and Industrial Research : Food Investigation. Special Report No. 41: The Freezing, Storage and Transport of New Zealand Lamb. By Dr. Ezer Griffiths, Dr. J. R. Vickery and N. E. Holmes. Pp. $\mathrm{x}+178+19$ plates. $78.6 d$. net.

2 Department of Scientific and Industrial Research: Food Investigation. Special Report No. 42: The Yellowing of the Abdominal Fa of Frozen Rabbits. By Dr. J. R. Vickery. Pp. iv +27. 6d. net.

Department of Scientific and Industrial Research. Index to the Literature of Food Investigation. Vol. 4, No. 1, March. Compiled by Agnes Elisabeth Glennie. Pp. iv +135 . 28. $6 d$. net.

(London: H.M. Stationery Office, 1932.)

\section{New Tank at the National Physical Laboratory}

$\mathrm{O}^{\mathrm{N}}$ November 18, in the presence of a large gathering of naval architects, shipowners, shipbuilders, engineers and others, Mr. Stanley Baldwin, Lord President of the Council, opened the New Tank at the William Froude Laboratory, which forms a part of the National Physical Laboratory, Teddington. The New Tank has

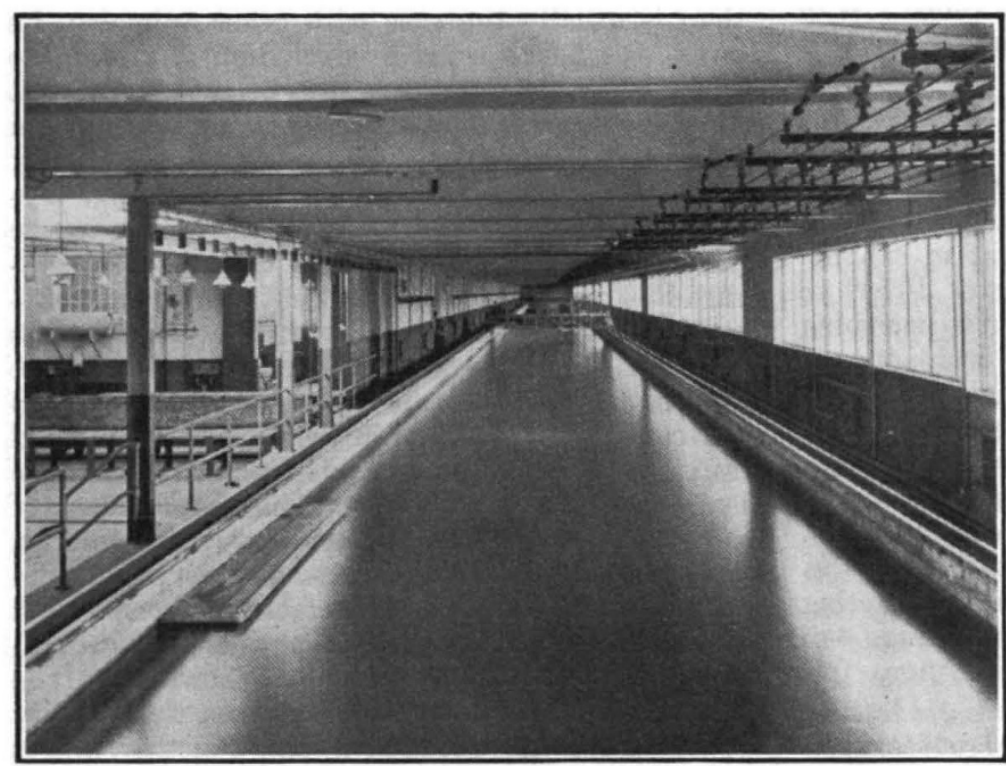

FIG. 1. The New Tank at the William Froude Laboratory

been built by the Government at a cost of $£ 45,000$ to meet the increased demand for model tests of ships' hulls, propellers and rudders, and like the Alfred Yarrow Tank, will be used in connexion with work for ships of the mercantile marine.

Referring to the work done in the Tank given to the Laboratory in 1910 by Sir Alfred Yarrow,
Mr. Baldwin remarked that, in 1928-29 it had become impossible, though the whole staff of the Laboratory was working overtime, to comply with all the requests made for assistance by shipbuilding firms. During the years 1927-1930, 188 designs of hulls were tested in the Tank and it was possible to show how designs could be improved in no fewer than 114 cases. Among the results obtained, and adopted in the shipbuilding industry largely through comprehensive researches in the Yarrow Tank are the introduction of the 'cruiser stern' on ordinary mercantile vessels, the introduction of 'aerofoil' types of propellers, the change of rake now common in single-screw ships and the use of a central fin on this type of ship to control inflow into the propeller.

At the conclusion of his address, Mr. Baldwin went aboard the carriage of the New Tank and watched an experiment with the new equipment for testing the efficiency of propellers working in open water. Visitors present also had an opportunity of witnessing this and other demonstrations. A number of model hulls together with their recording apparatus were on exhibition, and with these were the drawings of the projected Pro-

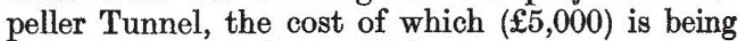
defrayed by Sir James Lithgow.

The New Tank (Fig. 1) consists of a monolithic ferro-concrete water basin $678 \mathrm{ft}$. long over all and $20 \mathrm{ft}$. wide at the water surface. The depth

No. 3291, VoL. 130] 